\title{
Growth inhibition and transcriptional effects of ribavirin in lymphoma
}

\author{
GUADALUPE DOMINGUEZ-GOMEZ ${ }^{1}$, DOMINIQUE CORTEZ-PEDROZA ${ }^{1}$, ALMA CHAVEZ-BLANCO ${ }^{1}$, \\ LUCIA TAJA-CHAYEB ${ }^{1}$, ALFREDO HIDALGO-MIRANDA ${ }^{2}$, ALBERTO CEDRO-TANDA ${ }^{2}$, \\ FREDY BELTRAN-ANAYA ${ }^{2}$, JOSE DIAZ-CHAVEZ ${ }^{1}$, ALEJANDRO SCHCOLNIK-CABRERA ${ }^{1}$, \\ AURORA GONZALEZ-FIERRO ${ }^{1}$ and ALFONSO DUEÑAS-GONZALEZ ${ }^{3}$
}

\begin{abstract}
${ }^{1}$ Division of Basic Research, National Cancer Institute (INCAN), Mexico City $14080 ;{ }^{2}$ Cancer Genomics Laboratory, National Institute of Genomic Medicine (INMEGEN), Mexico City 14610; ${ }^{3}$ Unit of Biomedical Research, Institute of Biomedical Research, National Autonomous University of Mexico (UNAM)/INCAN, Mexico City 14080, Mexico
\end{abstract}

Received November 3, 2018; Accepted June 20, 2019

DOI: $10.3892 / o r .2019 .7240$

\begin{abstract}
Ribavirin exhibits inhibitory effects on the epigenetic enzyme enhancer of zeste homolog 2 (EZH2), which participates in lymphomagenesis. Additionally, preclinical and clinical studies have demonstrated the anti-lymphoma activity of this drug. To further investigate the potential of ribavirin as an anticancer treatment for lymphoma, the tumor-suppressive effects of ribavirin were analyzed in lymphoma cell lines. The effects of ribavirin on the viability and clonogenicity of the B-cell lymphoma cell line Pfeiffer (EZH2-mutant), Toledo (EZH2 wild-type) and cutaneous T-cell lymphoma Hut78 cell line were assessed. Expression of EZH2 and trimethylation status of histone 3 , lysine 27 trimethylated (H3K27m3) was also determined in response to ribavirin. The transcriptional effects of ribavirin on Hut78 cells were analyzed by microarray expression and the results were validated by reverse transcription-quantitative polymerase chain reaction, western blotting and knockout of signal transducer and activator of transcription 1 (STAT1). The results of the present study demonstrated that ribavirin suppressed the growth and clonogenicity of cells in a dose-dependent manner. Ribavirin did not affect the expression of EZH2 nor altered its activity as evaluated by H3K27 trimethylation status. Furthermore, the results of transcriptome analysis indicated that the majority of the canonical pathways affected by ribavirin were associated with the immune system, including 'antigen presentation', 'communication between innate and adaptive immune cells' and 'cross-talk between dendritic and natural killer cells'.
\end{abstract}

Correspondence to: $\operatorname{Dr}$ Alfonso Dueñas-Gonzalez, Unit of Biomedical Research, Institute of Biomedical Research, National Autonomous University of Mexico (UNAM)/INCAN, 22 San Fernando Street, Mexico City 14080, Mexico

E-mail: alfonso_duenasg@yahoo.com

Key words: ribavirin, lymphoma, drug repositioning, EZH2, STAT1
The results of gene expression analysis were confirmed, by demonstrating at the RNA and protein levels, downregulation of stearoyl-CoA desaturase and upregulation of STATI. Depletion of STAT1, which was proposed as a key regulator of the aforementioned pathways, exerted growth inhibitory effects almost to the same extent as ribavirin. In conclusion, ribavirin was proposed to exert growth inhibitory effects on lymphoma cell lines, particularly Hut78 cells, a cutaneous T-cell lymphoma cell line. Of note, these effects may depend on, at least in part, the activation of canonical immune pathways regulated by the key factors STAT 1 and interferon- $\gamma$. Our results provide insight into the anti-lymphoma potential of ribavirin; however, further investigations in preclinical and clinical studies are required to determine the effectiveness of ribavirin as a therapeutic agent for treating lymphoma.

\section{Introduction}

The synthetic nucleoside analog 1- $\beta$-D-ribofuranosyl-1H-1, 2,4-triazole-3-carboxamide (ribavirin), is frequently used in combination with interferon (IFN)- $\alpha$ for the treatment of hepatitis $\mathrm{C}$ virus $(\mathrm{HCV})$ infection $(1,2)$ and is being repurposed as a therapeutic agent in the treatment of cancer (3). Ribavirin has demonstrated clinical activity in patients with relapsed or refractory acute myeloid leukemia of subtypes M4 and M5, and other subtypes with increased eukaryotic translation initiation factor 4E (eIF4E) levels. Of note, these clinical effects were reported in response to 5-36 $\mu \mathrm{M}$ ribavirin in the plasma (4). Our previous study revealed that ribavirin at clinically achievable concentrations $(<50 \mu \mathrm{M})$ exerted growth inhibitory effects in vitro upon certain cancer cell lines (3). Additionally, ribavirin inhibits eIF4E and inosine-5-monophosphate dehydrogenase (IMPDH) $(5,6)$. Ribavirin was determined to downregulate the expression of enhancer of zeste homolog 2 (EZH2), an epigenetic enzyme of the polycomb complex, at the RNA and protein levels, but also inhibited its activity, as demonstrated by reductions in histone 3, lysine 27 trimethylated (H3K27) trimethylation $(3,7,8)$. Gain-of-function heterozygous point mutations in the su(var)3-9, enhancer-of-zeste and trithorax-coding domain of the histone methyltransferase gene EZH2 has been 
reported in a subset of lymphomas. Increased expression or activity of EZH2 has been associated with lymphomagenesis; thus, EZH2 inhibition may be considered as a novel anticancer strategy $(9,10)$. Clinical studies with at least three EZH2 inhibitors are in progress against EZH2-mutant lymphomas (11).

Evidence has suggested that ribavirin may exhibit certain effects on lymphomas. Peveling-Overhag et al reported the overall response rate (ORR) of 254 patients (based on 20 studies) with B-cell non-Hodgkin lymphoma and HCV infection receiving antiviral therapy. The overall lymphoma response rate was $73 \%$, and a strong association between sustained serological viral response and lymphoma response (83\% ORR) was reported compared with those that failed to achieve a viral serological response (53\%). Improved response was observed in HCV-associated marginal zone lymphomas compared with that of non-marginal zone origin; however, the anti-lymphoma role of ribavirin remains uncertain as seven of these studies investigated IFN treatment only, while 12 studies analyzed the effects of IFN plus ribavirin, and one study evaluated the combination of rituximab, IFN and ribavirin (12).

To further investigate the effectiveness of ribavirin against lymphoma, the present study analyzed the antitumor properties of ribavirin in lymphoma cancer cell lines with and without EZH2 mutations.

\section{Materials and methods}

Cell lines, culture and ribavirin treatment. The following cell lines were used in the present study: Pfeiffer and Toledo, which are diffuse large B cell lymphoma (DLBCL) cells, and Hut78, which corresponds to a cutaneous T-cell lymphoma (CTCL). Cells were obtained from the American Type Culture Collection (ATCC; Manassas VA, USA). The Pfeiffer cell line carries the A677G mutation in $E Z H 2$, while Toledo cells are wild-type. Cells were cultured at $37^{\circ} \mathrm{C}$ in a humidified atmosphere containing $5 \% \mathrm{CO}_{2}$ in complete medium, comprising RPMI-1640 medium supplemented with $10 \%$ fetal bovine serum and 1\% antibiotic-antimycotic solution (all from Invitrogen; Thermo Fisher Scientific, Inc., Waltham, MA, USA). Ribavirin was obtained from Sigma-Aldrich (Merck KGaA, Darmstadt, Germany); 3-deazaneplanocin A (DZNep) served as the control and was purchased from Calbiochem (cat. no. 120964-45-6). Ribavirin and DZNep were dissolved in RPMI-1640 medium, stored at $-20^{\circ} \mathrm{C}$ and thawed before use. Stock solutions were thawed/frozen no more than three times. Cell lines were treated with $10,15,20,25$ and $50 \mu \mathrm{M}$ of ribavirin, or $0.1 \mu \mathrm{M}$ DZNep for 24,48 and $120 \mathrm{~h}$.

Cell viability assay. Cells were seeded in $25-\mathrm{cm}^{2}$ culture flasks (Corning Inc., Corning, NY, USA) at a density of $2 \times 10^{5}$ cells in $5 \mathrm{ml}$ of complete medium. Cells were then treated with ribavirin at the indicated concentrations; the medium containing the drug was replaced daily. DZNep at a concentration of $0.1 \mu \mathrm{M}$ was used as a positive control. After 24,48 and $120 \mathrm{~h}$, cells were stained with $0.4 \%$ trypan blue to assess cell viability and counted using a TC10 Automated Cell Counter (Bio-Rad Laboratories, Inc., Hercules, CA, USA). All assays were performed in triplicate. The viability of cells under each treatment condition was expressed as a percentage of cell count relative to the untreated control cells.
Clonogenic assay. Exponentially proliferating cells $\left(2 \times 10^{5}\right)$ were plated in a $25-\mathrm{cm}^{2}$ cell culture flask and incubated in RPMI-1640 medium and treated with ribavirin (10, 25 and $50 \mu \mathrm{M})$ or DZNep $(0.1 \mu \mathrm{M})$ for $120 \mathrm{~h}$. Untreated cells served as the negative control. After $120 \mathrm{~h}$ of treatment, the cells were collected; $2 \times 10^{3}$ cells were seeded into $25-\mathrm{cm}^{2}$ culture flasks for $\leq 16$ days in complete drug-free medium. The medium was discarded every $48 \mathrm{~h}$ and replaced with complete fresh medium. Cells were cultured for 16 days, after which the viability of cells was determined by a trypan blue exclusion assay using a TC10 Automated Cell Counter (Bio-Rad Laboratories, Inc.).

Statistical analyses. Three independent experiments in triplicate were performed, and data are expressed as the mean \pm standard deviation. Data were statistically analyzed using GraphPad Prism V6 software (GraphPad Software Inc., La Jolla, CA, USA). Significant differences were determined using one-way analysis of variance (ANOVA) followed by Bonferroni correction to determine significant differences between each experimental group against its respective control. $\mathrm{P}<0.05$ was considered to indicate a statistically significant difference.

Protein extraction and western blotting. Hut78 cells $\left(2.5 \times 10^{5}\right)$ were cultured in $25-\mathrm{cm}^{2}$ flasks and treated with ribavirin for $120 \mathrm{~h}$. Once cells were washed with PBS and centrifuged for $120 \mathrm{x} \mathrm{g}$ for $5 \mathrm{~min}$, proteins were extracted using radioimmunoprecipitation buffer $(150 \mathrm{mM} \mathrm{NaCl} ; 1.0 \%$ IGEPAL CA630; $0.5 \%$ sodium deoxycholate; $0.1 \%$ SDS and $50 \mathrm{mM}$ Tris, $\mathrm{pH}$ 8.0) in the presence of proteinase inhibitors (cat. no. p8340; Sigma-Aldrich; Merck KGaA). The protein concentration was determined using a bicinchoninic acid assay (BCA-1, Bio-Rad Laboratories, Inc.) and the integrity was assessed by Coomassie staining. A total of $30 \mu \mathrm{g}$ protein was separated by $10 \%$ SDS PAGE and transferred onto a polyvinylidene difluoride membrane (cat. no. 1620177; Bio-Rad Laboratories, Inc.). The membrane was blocked with 5\% skim milk in PBS for $1 \mathrm{~h}$ at room temperature and subsequently incubated with antibodies against EZH2 (cat. no. 36-6300; 1:500, Invitrogen; Thermo Fisher Scientific, Inc.), STAT-1 (cat. no. sc417; 1:200, Santa Cruz Biotechnology, Inc., Dallas, TX, USA) and SCD (cat. no. sc58420; 1:500,) (Santa Cruz Biotechnology, Inc.), and anti-actin peroxidase (cat. no. A3854; 1:10,000, Sigma Aldrich; Merck KGaA) in blocking solution (5\% skim milk in TBS $+0.1 \%$ Tween-20), overnight at $4^{\circ} \mathrm{C}$. The following secondary antibodies were used: for EZH2, anti-rabbit (cat. no. sc2370) and for STAT-1 and SCD, anti-mouse (cat. no. sc2371), which were obtained from Santa Cruz Biotechnology, Inc. The secondary antibodies were diluted 1:1,000 and the incubation was performed for $1 \mathrm{~h}$ at room temperature. Protein bands were visualized using Clarity Western Enhanced Chemiluminescence Substrate (cat. no. 1705060; Bio Rad Laboratories, Inc.). Bands were quantified densitometrically using ImageJ version $1.50 \mathrm{f}$ (National Institutes of Health, Bethesda, MD, USA).

Extraction, purification, and analysis of histones. Histone proteins were isolated via the sulfuric acid extraction method. Briefly, the nuclear pellet was resuspended in $0.4 \mathrm{M} \mathrm{H}_{2} \mathrm{SO}_{4}$ for $4 \mathrm{~h}$; following centrifugation (10,000 x g, $20 \mathrm{~min})$, acid-soluble 
proteins in the supernatant were obtained via overnight precipitation with $20 \%$ trichloroacetic acid and centrifugation (16,000 x $\mathrm{g}$ for $30 \mathrm{~min})$. The pellets containing histone proteins were washed once in ice-cold acetone containing $1 \% \mathrm{HCl}$ and followed by ice-cold acetone alone. The pellet was dried under vacuum and stored at $-80^{\circ} \mathrm{C}$. The protein concentration was determined by the Bradford method, and the integrity of the histone proteins in the acid-soluble extract was evaluated using Coomassie staining. Proteins were separated via $15 \%$ SDS-PAGE and then transferred to a polyvinylidene difluoride membrane (Bio-Rad Laboratories, Inc.). The membrane was incubated for $1 \mathrm{~h}$ with blocking solution (TBS-Tween-20, $5 \%$ of non-fat milk) followed by overnight incubation with antibodies, including anti-H3K27me3 (cat. no. 07-449) and anti-H3 total (cat. no. 06-755) obtained from EMD Millipore (Billerica, MA, USA). Anti-rabbit secondary antibody (cat. no. sc2370; 1:1,000, Santa Cruz Biotechnology, Inc) was then applied for $1 \mathrm{~h}$ at room temperature. Protein bands were visualized using the chromogenic substrate Clarity Western Enhanced Chemiluminescence Substrate (cat. no. 1705060 , Bio-Rad Laboratories, Inc.). Bands were quantified densitometrically using ImageJ software.

Microarrays and gene expression analysis. Hut78 cells were treated with $50 \mu \mathrm{M}$ ribavirin for $120 \mathrm{~h}$ as aforementioned and then total RNA was isolated using TRIzol (Thermo Fisher Scientific, Inc.), according to the manufacturer's protocols. RNA quality was evaluated by capillary electrophoresis (Agilent 2100 Bioanalyzer, Agilent Technologies, Inc., Santa Clara, CA, USA); only RNA samples with an RNA integrity number $>8.0$ were further processed for microarray analysis. A total of $200 \mathrm{ng}$ RNA from each experimental cell group was evaluated using the Gene Chip Human Transcriptome Array 2.0 (Affymetrix; Thermo Fisher Scientific, Inc.) to determine the whole transcriptome expression profiles according to the manufacturer's protocols. Briefly, the synthesis and amplification of cDNA, and gene expression profiling were conducted using the WT PLUS Reagent Kit for fresh samples (Affymetrix; Thermo Fisher Scientific, Inc.). Washing and staining of the samples were performed using the Gene chip hybridization wash and stain kit in the Gene Chip Fluidics Station 450 system (Affymetrix; Thermo Fisher Scientific, Inc.). The probe arrays were scanned using The Gene Chip Scanner 30007G (Affymetrix; Thermo Fisher Scientific, Inc.). Signal intensities of the array were analyzed with Affymetrix Expression Console software (version 1.3). Briefly, raw data probes were normalized using Signal Space Transformation-Robust Multichip Analysis for background correction and to obtain the quantile algorithm. To define the differential expression profiles of the different conditions, two-way ANOVA was performed in the Affymetrix Transcriptome Analysis Console software (version 3.0). Genes with a fold change $>2$ or $<2$ and with an $\mathrm{P} \leq 0.05$ (obtained via ANOVA) were considered significantly altered between the conditions. All data were uploaded in Gene Expression Omnibus: GSE118866, token: Klujuowqpnsvpkl.

Bioinformatics analysis. Gene Ontology analysis was performed using Protein Analysis Through Evolutionary Relationship (http://www.pantherdb.org). Molecular pathways and interaction networks were analyzed by Ingenuity Pathway Analysis (Ingenuity Systems Inc., Redwood City, CA, USA).

Reverse transcription-quantitative polymerase chain reaction $(R T-q P C R)$. Hut78 cells were treated with ribavirin for $120 \mathrm{~h}$, and total RNA was isolated when cells attained $\sim 70 \%$ confluence, using TRIzol reagent according to the manufacturer's protocols. RNA purity and integrity were assessed via spectrophotometric analysis using a NanoDrop 2000c spectrophotometer (NanoDrop Technologies; Thermo Fisher Scientific, Inc., Wilmington, DE, USA) and denaturing $2 \%$ agarose gel. Bands were visualized using a MiniBIS Pro D-Transilluminator (DNR Bio-Imaging Systems Ltd., Neve Yamin, Israel). A total of $1 \mu \mathrm{g}$ total RNA was used for cDNA synthesis with the GeneAmp RNA PCR Core kit (Applied Biosystems; Thermo Fisher Scientific, Inc.). iQ SYBR Green SuperMix (Bio-Rad Laboratories, Inc.) was used according to the manufacturer's protocols. qPCR reactions were run in triplicate using an ABI PRISM 7000 (Applied Biosystems; Thermo Fisher Scientific, Inc.). The thermocycling conditions for qPCR were as follows: $10 \mathrm{~min}$ at $95^{\circ} \mathrm{C} ; 40$ cycles of $30 \mathrm{sec}$ at $95^{\circ} \mathrm{C}$ and $30 \mathrm{sec}$ at $60^{\circ} \mathrm{C}$. Data were analyzed using the $2^{-\Delta \Delta \mathrm{Cq}}$ method (12), and reported as the fold-change in gene expression normalized to the endogenous control gene hypoxanthine phosphoribosyltransferase 1 (HPRT1), and relative to untreated cells. The primers used were: HPRT1 forward, 5'-GAACCTCTCGGCTTTCCCG-3' and reverse, 3'-CAC TAATCACGACGCCAGGG-5'; STAT-1 forward, 5'-ATGCTG GCACCAGAACGAAT-3' and reverse, 3'-GCTGGCTGACGT TGGAGATC-5'; and SCD forward 5'-GGGATCCTTCAG CACAGGAA-3' and reverse 3'-CACCGCTTCTCCAATGGA TT-5'. Annealing temperatures were $60^{\circ} \mathrm{C}$ for all reactions. Three independent triplicates were conducted. P-values were calculated using a two-tailed t-test.

Signal transducer and activator 1 short hairpin (sh)RNA lentiviral gene silencing. Hut78 cells were plated $\left(2 \times 10^{5}\right)$ in a 6 -well plate $24 \mathrm{~h}$ prior to viral infection with $1 \mathrm{ml}$ of complete optimal medium (with serum and antibiotics) and were incubated overnight at $37^{\circ} \mathrm{C}$ and $5 \% \mathrm{CO}_{2}$. Then, the medium was removed from the wells and replaced with $1 \mathrm{ml}$ of complete medium with Polybrene (cat. no. sc-134220, Santa Cruz Biotechnology, Inc.) at a final concentration of $2 \mu \mathrm{g} / \mathrm{ml}$. Lentiviral particles were thawed at room temperature and mixed gently before use. Subsequently, cells were infected by adding STAT-1 shRNA Lentiviral Particles (cat. no. sc-44123V, Santa Cruz Biotechnology, Inc.) to the culture and centrifuged at 2,460 x $\mathrm{g}$ for $1 \mathrm{~h}$, and then mixed for $6 \mathrm{~h}$ at $37^{\circ} \mathrm{C}$ in $5 \% \mathrm{CO}_{2}$. Control shRNA Lentiviral Particles (cat. no. sc-108080, Santa Cruz Biotechnology, Inc.) were used. The next day, the culture medium was removed and replaced with $1 \mathrm{ml}$ of complete medium (without Polybrene) and cells were incubated overnight at $37^{\circ} \mathrm{C}$ in $5 \% \mathrm{CO}_{2}$. Then, the shRNA Lentiviral Particles were diluted 1:3 according to the manufacturer's instructions and added to the cells; the cells were incubated for 24-48 $\mathrm{h}$ in complete medium. The clones expressing the shRNA were selected with puromycin, and the medium was replaced with fresh puromycin-containing medium every 3-4 days until resistant cells could be identified. Cell viability assays were 

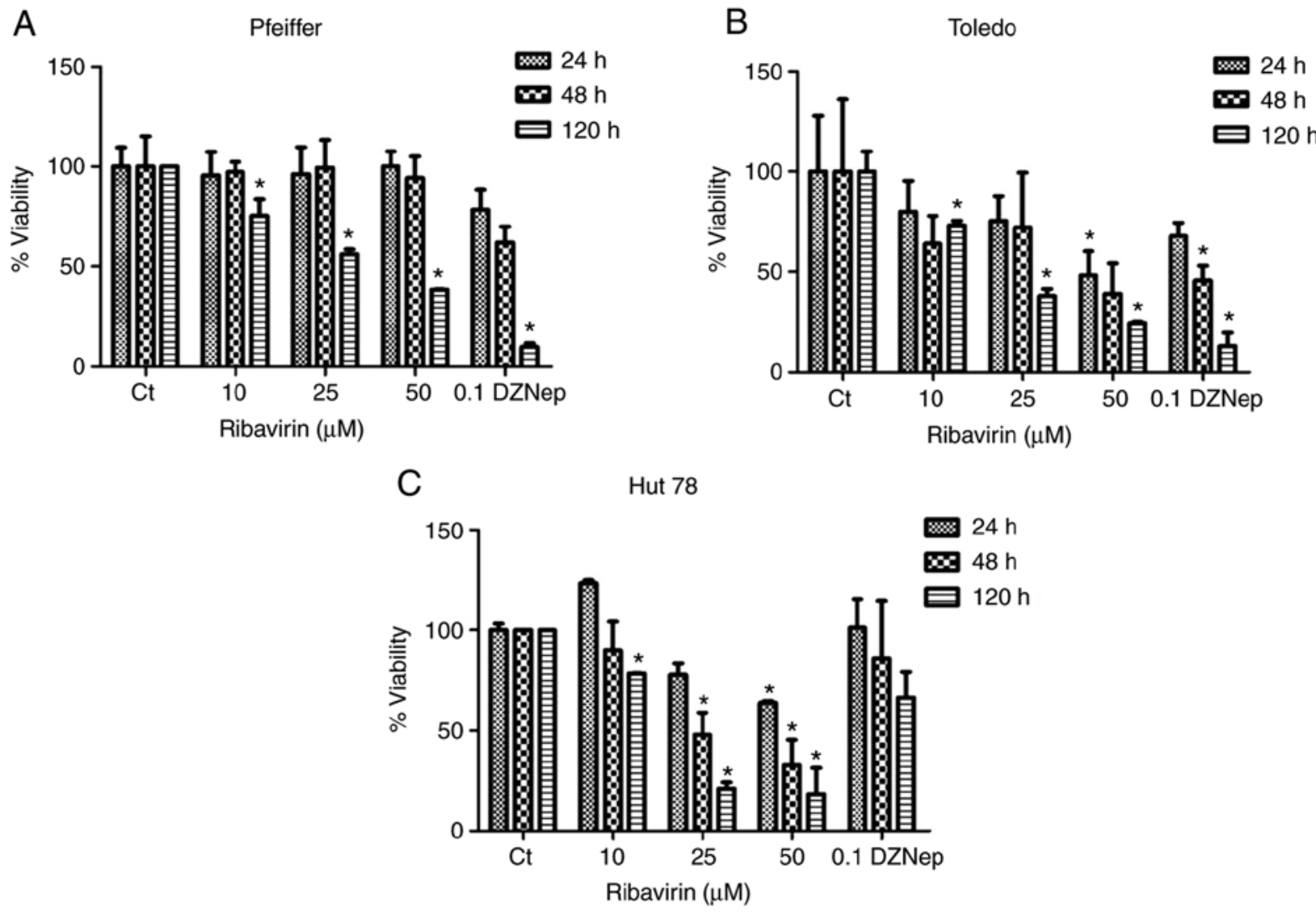

Figure 1. Viability of Pfeiffer (A) and Toledo (B), diffuse large B cell lymphoma cells, and Hut78 (C), a cutaneous T-cell lymphoma cell line. Cells were treated with ribavirin at different concentrations and for different time periods. 3-Deazaneplanocin A (DZNep) was used as a positive control. Statistically significant difference, ${ }^{*} \mathrm{P}<0.05$. To note, the Pfeiffer cell line carries the A677G mutation in EZH2, while Toledo cells are wild-type.

performed using cells treated with $50 \mu \mathrm{M}$ ribavirin for $120 \mathrm{~h}$ as aforementioned. The experiments were conducted with at least three independent triplicates. P-values were calculated using one-way ANOVA with Bonferroni correction.

\section{Results}

Ribavirin suppresses cell viability. Lymphoma cells were exposed to different concentrations of ribavirin and the cell viability was analyzed at $120 \mathrm{~h}$ post-treatment. As presented in Fig. 1A-C, a dose-dependent effect of different extents was observed in the cell lines. For Pfeiffer cells, no inhibition at 24 and $48 \mathrm{~h}$ was reported regardless of the dose of ribavirin administered; however, a significant effect was observed with the three concentrations at $120 \mathrm{~h}$. Inhibition with DZNep revealed a significant effect at $120 \mathrm{~h}$. For Toledo cells, suppressed cell viability was observed following treatment with $25 \mu \mathrm{M}$ ribavirin for $120 \mathrm{~h}$, and with $50 \mu \mathrm{M}$ ribavirin at 24 and $120 \mathrm{~h}$. DZNep treatment also revealed a significant effect on cell viability at 48 and $120 \mathrm{~h}$. In the CTCL cell line Hut78, significant inhibition was observed with $25 \mu \mathrm{M}$ ribavirin at $48 \mathrm{~h}$ and $120 \mathrm{~h}$ as well while $50 \mu \mathrm{M}$ exhibited inhibitory effects at 24,48 and $120 \mathrm{~h}$. Of note, this cell line appeared to be the most sensitive to ribavirin, but less so to DZNep.

Ribavirin inhibits clonogenicity. A clonogenic assay was conducted to determine the colony formation ability of cells.
The results suggested that the colony formation ability of Pfeiffer cells was significantly inhibited with all doses of ribavirin. On the contrary, the colony formation ability of Toledo cells was markedly unaffected in response to ribavirin; however, significant inhibition was observed following treatment with DZNep. In the CTCL cell line Hut78, a significant decrease in clonogenicity was observed in response to $50 \mu \mathrm{M}$ ribavirin, while DZNep did not change the clonogenicity of this cell line (Fig. 2A-C).

Effects of ribavirin on EZH2 protein expression and $H 3 K 27$ trimethylation. To determine whether the effects of ribavirin on the viability and clonogenicity of the lymphoma cell lines were associated with EZH2 and $\mathrm{H} 3 \mathrm{~K} 27 \mathrm{~m} 3$, cells were treated for $72 \mathrm{~h}$ with the aforementioned doses of ribavirin and DZNep. The results indicated that the expression of EZH2 was markedly unaffected in response to ribavirin in the cell lines, whereas a notable reduction in Pfeiffer cells was observed following treatment with DZNep (Fig. 3A). Of note, no marked reductions in $\mathrm{H} 3 \mathrm{~K} 27$ trimethylation were reported in response to ribavirin (Fig. 3B).

Effects of ribavirin on gene expression in Hut78 cells. A total of 978 genes were reported to be differentially expressed. Among these, 629 were upregulated and 349 were downregulated. Ingenuity Pathway Analysis of the microarray results (Table I) revealed that $K L H D C 7 B, P T G S 2, G B P 1, S T A T 1, G B P 5$, $G B P 2, G B P 4, W A R S, R G S 1$ and GBPIPI were the top 10 most 

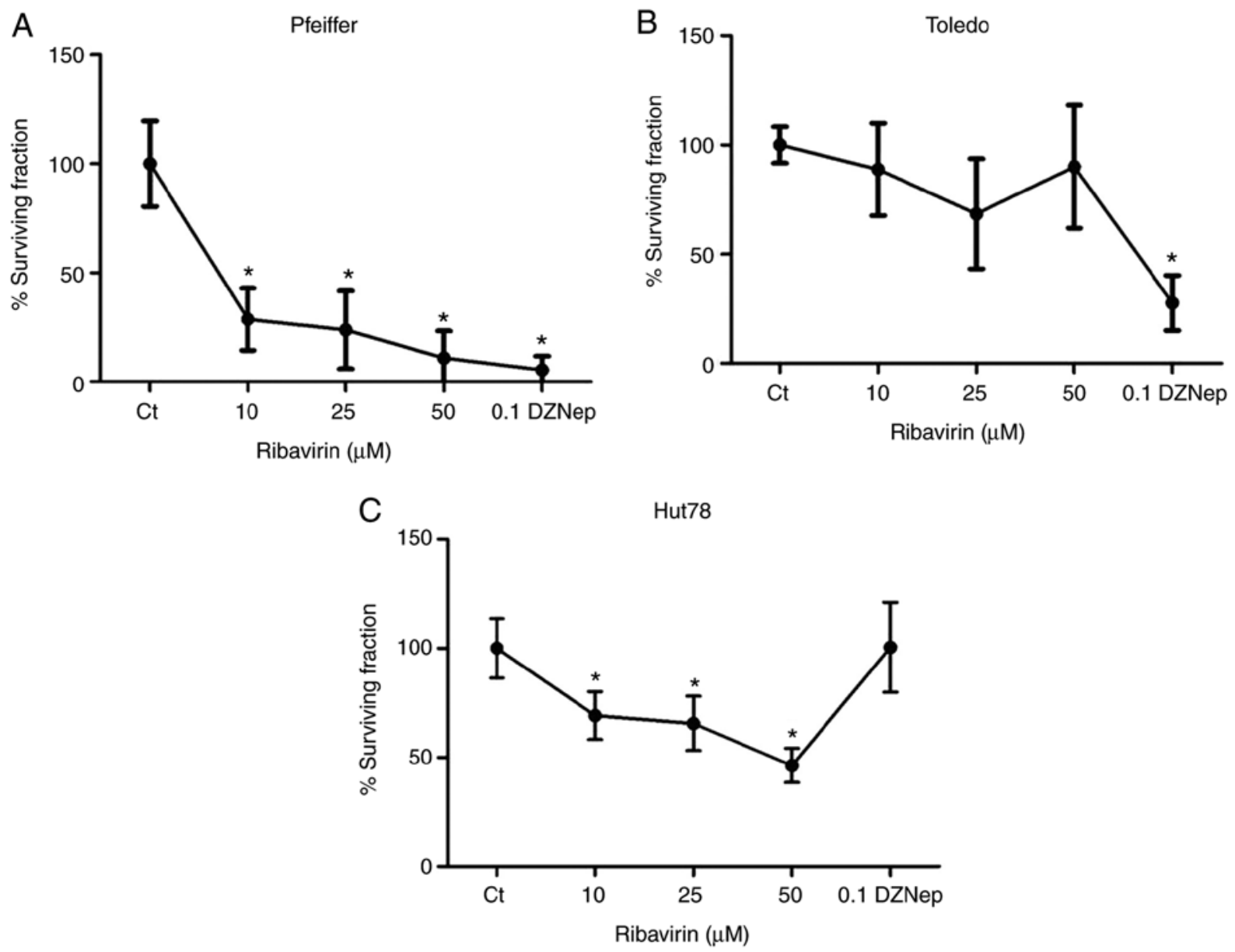

Figure 2. Clonogenicity of Pfeiffer (A) and Toledo (B), diffuse large B cell lymphoma cells, and Hut78 (C), a cutaneous T-cell lymphoma cell line. Cells were treated with ribavirin at different concentrations and for different time periods. 3-Deazaneplanocin A (DZNep) was used as a positive control. Statistically significant difference, ${ }^{*} \mathrm{P}<0.05$. To note, the Pfeiffer cell line carries the A677G mutation in EZH2, while Toledo cells are wild-type.
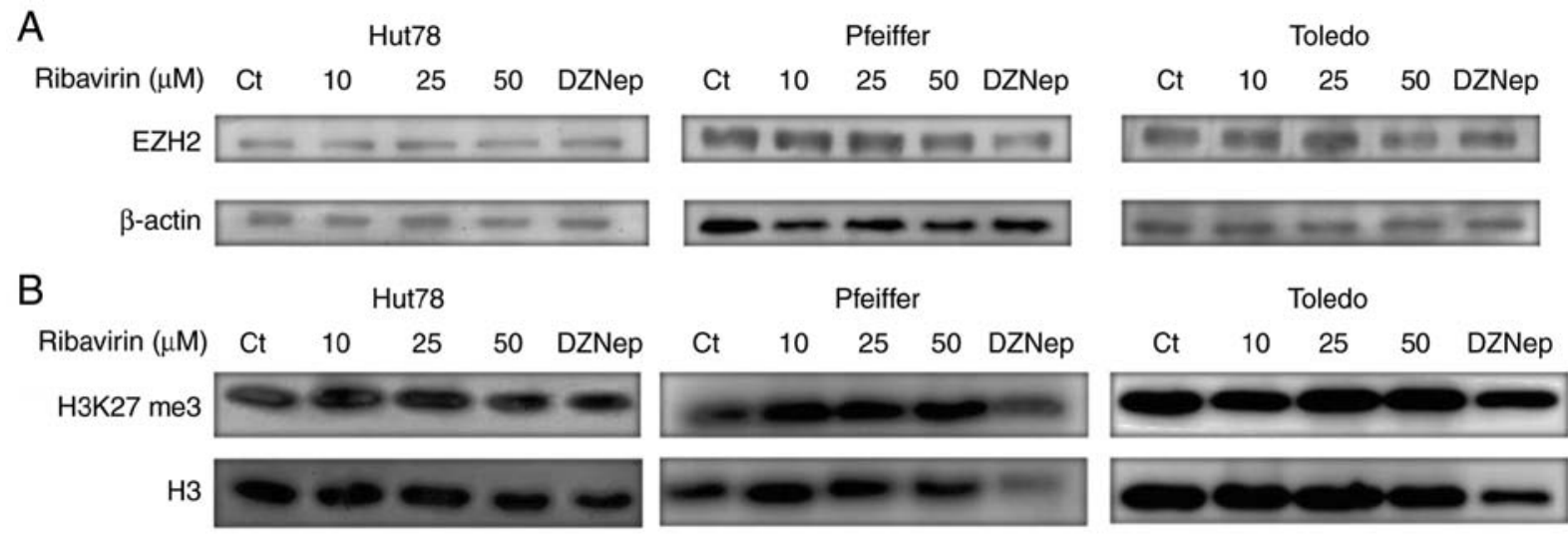

Figure 3. Effects of ribavirin upon EZH2 expression (A) and H3K27m3 (B) in Pfeiffer and Toledo, diffuse large B cell lymphoma cells, and Hut78, a cutaneous T-cell lymphoma cell line. The expression of EZH2 was mostly unchanged but showed a small (non-significant) decrease with DZNep in mutant Pfeiffer cells. No changes in H3K27m3 were observed. To note, the Pfeiffer cell line carries the A677G mutation in EZH2, while Toledo cells are wild-type. EZH2, enhancer of zeste homolog 2; H3K27m3, trimethylation status of histone 3, lysine 27 trimethylated.

upregulated genes, while $S C D, T I M P 2$, GIPC3, DUSP9, $C D 5$, TCF7, RFLNB, SBK1, LGMN and SMIM24 were the most downregulated. The top canonical pathways most significantly affected by ribavirin treatment included 'antigen presentation', 'communication between innate and adaptive immune cells', 'cross-talk between dendritic and natural killer cells', 'unfolded protein response' and 'allograft rejection'. The top regulators of these pathways were determined to be STATI, $I F N-\gamma, R E L A, I F N-\alpha$ and IFN- $\alpha 2$.

Gene validation of the transcriptional effects and knockout of STATI. STAT1 and SCD, which were determined to be 
Table I. List of the 10 most upregulated genes and the 10 most downregulated genes in Hut78 cells following ribavirin treatment.

\begin{tabular}{lc} 
Upregulated molecules & Expression fold-change value \\
\hline$K L H D C 7 B$ & $\uparrow 53.590$ \\
$P T G S 2$ & $\uparrow 52.680$ \\
$G B P 1$ & $\uparrow 28.730$ \\
STAT1 & $\uparrow 28.330$ \\
$G B P 5$ & $\uparrow 21.080$ \\
$G B P 2$ & $\uparrow 18.550$ \\
$G B P 4$ & $\uparrow 12.990$ \\
$W A R S$ & $\uparrow 11.170$ \\
$R G S 1$ & $\uparrow 10.200$ \\
$G B P 1 P 1$ & $\uparrow 9.950$ \\
\hline
\end{tabular}

Downregulated molecules

Expression fold-change value

\begin{tabular}{lr}
\hline SCD & $\downarrow-11.150$ \\
TIMP2 & $\downarrow-7.780$ \\
GIPC3 & $\downarrow-5.610$ \\
DUSP9 & $\downarrow-5.500$ \\
$C D 5$ & $\downarrow-5.240$ \\
TCF7 & $\downarrow-4.820$ \\
RFLNB & $\downarrow-4.490$ \\
SBK1 & $\downarrow-4.450$ \\
LGMN & $\downarrow-3.980$ \\
SMIM24 & $\downarrow-3.900$
\end{tabular}

$\uparrow$, upregulated; $\downarrow$, downregulate. $K L H D C 7 B$, kelch domain containing 7B; $P T G S 2$, prostaglandin-endoperoxide synthase 2; $G B P 1$, guanylate binding protein $1 ; S T A T 1$, signal transducer and activator of transcription 1; GBP5, guanylate binding protein 5; GBP2, guanylate binding protein $2 ; G B P 4$, guanylate binding protein 4 ; WARS, tryptophanyl-TRNA synthetase; $R G S 1$, regulator of $\mathrm{G}$ protein signaling 1; GBP1P1, guanylate binding protein 1 pseudogene 1; $S C D$, stearoyl-CoA desaturase; TIMP2, TIMP metallopeptidase inhibitor 2; GIPC3, GIPC PDZ domain containing family member 3; DUSP9, dual specificity phosphatase 9; CD5, CD5 molecule; TCF7, transcription factor 7; RFLNB, refilin B; SBK1, SH3 domain binding kinase 1; LGMN, legumain; SMIM24, small integral membrane protein 24 .

upregulated and downregulated, respectively, were analyzed by RT-qPCR and western blotting. The results demonstrated that in both cases, STAT1 expression was increased, while that of $S C D$ was decreased at the RNA and protein levels; these differences were statistically significant (Fig. 4A-D). As STAT1 was proposed as a top regulator of the central canonical pathways determined to be altered in microarray analysis, this gene was deleted using shRNA. As presented in Fig. 5, an $\sim 70 \%$ reduction in cell viability was observed following STAT1-shRNA Lentiviral Particles knockout; however, cell viability was markedly unaffected in response to the scramble control miRNA. Treatment with ribavirin of STAT1-depleted cells further decreased cell viability; these differences were statistically significant.

\section{Discussion}

The results of the present study revealed that ribavirin inhibited the growth and clonogenicity of cells in a dose-dependent manner in certain lymphoma cell lines. These effects were not related to the mutational status of EZH2; the expression and activity of $E Z H 2$ were markedly unaffected by ribavirin as evaluated by RT-qPCR and H3K27 trimethylation analysis, respectively. Furthermore, the results of transcriptome analysis indicated that the majority of the canonical pathways affected by ribavirin were associated with the immune system, including 'antigen presentation', 'communication between innate and adaptive immune cells' and 'cross-talk between dendritic and natural killer cells'. Analysis of expression at the mRNA and protein levels revealed that $S C D$ was downregulated, while STAT1 was upregulated. Depletion of STAT1, which was proposed as a top regulator of the aforementioned pathways, exerted growth inhibitory effects almost to the same extent as ribavirin.

Our results revealed the antitumor effects of ribavirin. The inhibition of cell growth, differentiation and migration by ribavirin has been observed in numerous cancer cell lines, including breast, cervical, colon, brain, prostate, head and neck, and lung cancer. These effects may occur by inhibiting eIF4E, EZH2 and IMPDH (3,13-20); however, the majority of studies into the antitumor effects of ribavirin have focused on eIF4E, which is directly targeted by ribavirin $(5,21-23)$. In addition, in models of aggressive double- and triple-hit diffuse large B-cell lymphomas, eIF4E inhibition mediated by ribavirin resulted in tumor-suppressive effects in cell lines and patient-derived tumor grafts (24). Based on the fact that anti-lymphoma activity in patients has been reported following treatment with ribavirin $(12,25)$, as well as in light of our previous findings of downregulated EZH expression and activity in MCF-7 cells (3), we investigated the effects of ribavirin in lymphoma cell lines. The present study reported that, regardless of $E Z H 2$ mutation, ribavirin exhibited inhibitory effects in certain lymphoma cell lines. As notable inhibition with DZNep was also observed, it was proposed that ribavirin is likely to exert its effects independent of EZH2, at least in the cell lines employed in the present study.

On the contrary, significant inhibition was observed in the CTCL cell line following treatment with ribavirin, but not with DZNep, suggesting that other mechanisms may be involved in this phenomenon. Thus, global gene expression analysis was conducted in the present study to further investigate the mechanisms underlying the effects of ribavirin in T-cell lymphoma. The present study determined that ribavirin affects the transcription of genes as alterations in the expression of 978 genes were reported; the majority of genes were upregulated, including STATI and IFN- $\gamma$. IFNs and other cell signals have been proposed to activate STAT1. Following activation, STAT1 translocates to the nucleus to induce IFN-stimulated genes associated with antiviral defense, tumor-suppressive functions and the immune surveillance of tumors (26-28). Analysis of STATl knockout in the present study may provide further insight into the role of STAT1 as the inhibitory effects exerted on Hut78 cells were similar to the effects of ribavirin.

To the best of our knowledge, no studies have investigated the transcriptomic response of cancer cells to ribavirin. 
A

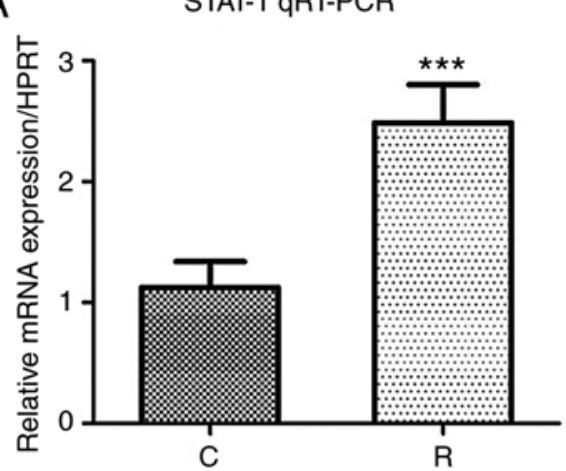

B

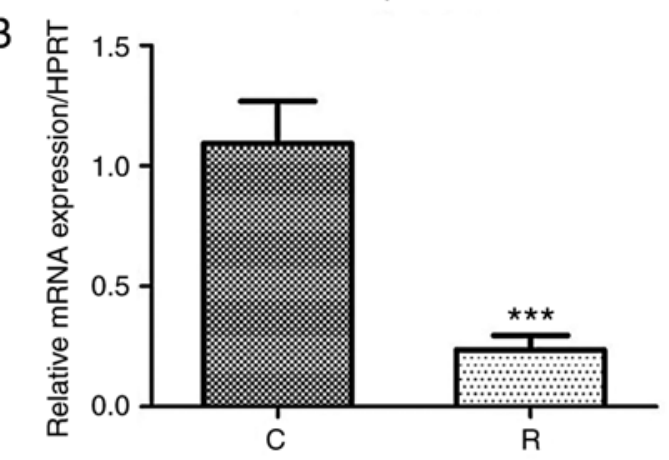

C

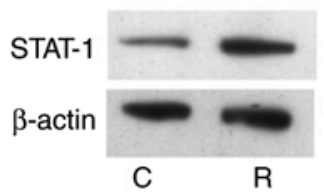

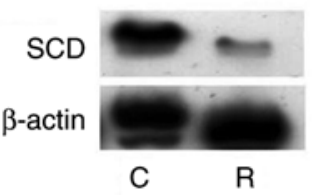

D
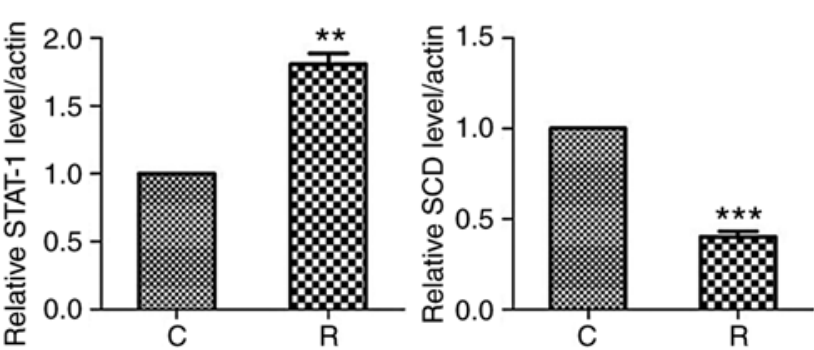

Figure 4. Validation of STAT1 and SCD genes by qRT-PCR and western blot analysis in Hut78 cells. (A and B) Relative expression of STAT-1 and SCD adjusted for HPRT show a statistically significant increase and decrease, respectively, in the Hut78 cells following ribavirin treatment. ${ }^{* * *} \mathrm{P}<0.00$, compared to the control. (C and D) Expression changes were also observed at the protein levels. ${ }^{* *} \mathrm{P}<0.01$ for STAT-1 and ${ }^{* * *} \mathrm{P}<0.001$ for SCD. C, control; R, ribavirin. STAT1, signal transducer and activator of transcription 1; SCD, stearoyl-CoA desaturase.

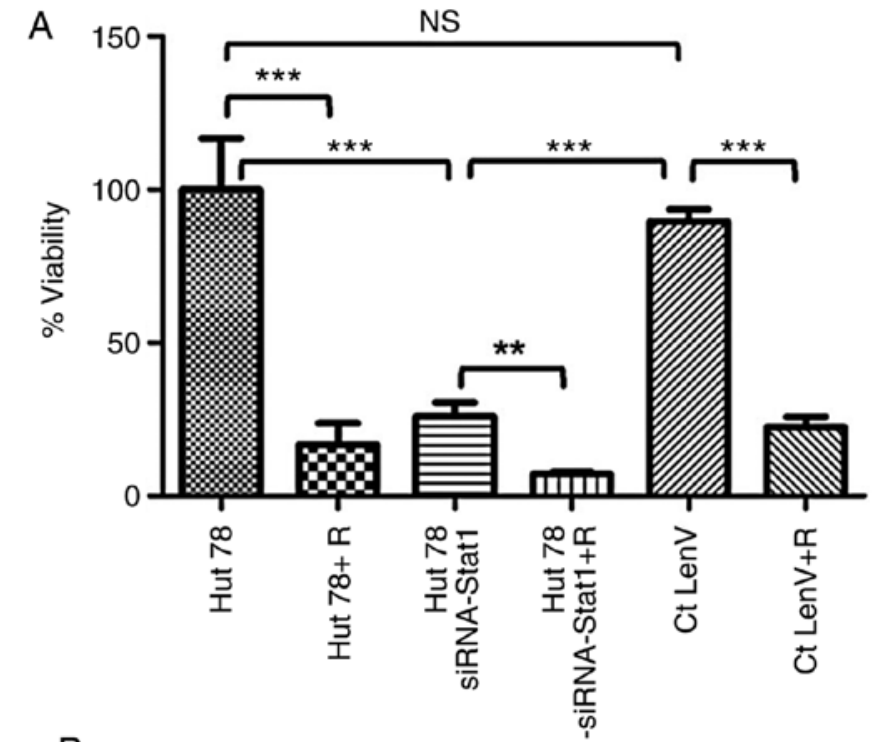

B

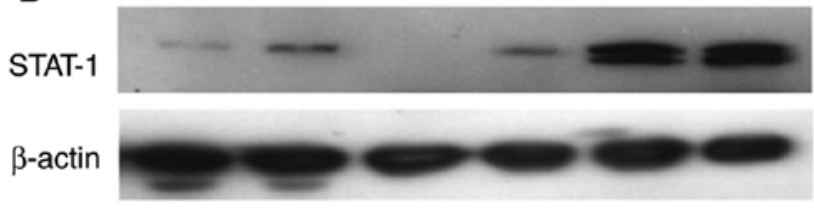

Figure 5. Effects of the knockout of STAT1 on cell viability. (A) No differences in viability were observed between untreated cells (Hut78) and scramble transfected cells (Ct LenV) while depletion of STAT1 (Hut78 shRNA-Stat1) decreased viability as compared to the untreated and scramble transfected cells $\left.{ }^{(* * *} \mathrm{P}<0.001\right)$, and was further decreased following treatmen with ribavirin $\left({ }^{* *} \mathrm{P}<0.01\right)$. In both, control and scrambled control transfected, ribavirin decreased cell viability $\left({ }^{* * *} \mathrm{P}<0.001\right)$. NS, not significant. (B) The absence of a protein band in the Hut78 shRNA-STAT1 cells is shown and it was also demonstrated that ribavirin slightly induced STAT-1 protein. STAT1, signal transducer and activator of transcription 1. R, ribavirin.
However, this response was determined in the liver of patients with chronic HCV infection. Gene expression analysis of liver biopsies of patients treated with ribavirin revealed no significant effects on hepatic gene expression in response to ribavirin compared with controls. Similar results were obtained following treatment with ribavirin combined with PEG-IFN than PEG-IFN alone; however, significant downregulation in the expression of IFN-stimulated genes was reported in the liver, but not in peripheral blood cells (29). The findings of the present study in a CTCL lymphoma cell line supports the importance of the IFN-STAT1 signaling pathway in CTCL. Sun et al investigated the development of the IFN-resistant Hut78 cell line. Although the expression levels of the IFN receptor and its binding affinity were comparable between parental and resistant cells, IFN- $\alpha$ stimulation failed to induce IFN-stimulated gene factor 3 complex formation in IFN-resistant Hut78R cells. This may be associated with downregulated STAT1 protein or mRNA expression, suggesting that at least in this model, STAT1 may be required for the antitumor effects of IFN (30). IFN- $\gamma$ was used in a phase II trial with 15 patients, 11 (73.3\%) of whom achieved an objective response (31). A recent study reported on 6 patients with CTCL (mycosis fungoides) and HCV infection who received antiviral treatment; 3 patients received PEG-IFN plus ribavirin. A total of 2 patients exhibited stabilization of skin lesions with marked improvement in pruritus, while another had a complete response that was maintained for 5-years at the time of analysis (32). At present, the majority of studies that reported non-Hodgkin lymphoma with IFN and ribavirin treatment investigated B-cell lymphoma; the direct inhibition of eIF4E has been notably evaluated $(24,25)$. The results of the present study on the DLBCL cell lines, Pfeiffer with an 
EZH2 mutation and Toledo with no mutation, revealed inhibition of cell growth in response to ribavirin. A limitation of this study is that transcriptome analysis was limited to the CTCL cell line; thus, it cannot be suggested that the same transcriptional response to ribavirin may be observed in all B-cell lymphomas. Nevertheless, in an analysis of 2,030 cases of DLBCL from 10 publicly available gene expression datasets, polarized T-cell and cytotoxic gene expression in association with the IFN- $\gamma / \mathrm{STAT} 1 / \mathrm{IRF} 1$ axis was reported. To note, such a response may be related to improved outcome, particularly in the germinal center B-cell subsets of DLBCL (33).

In conclusion, the results of the present study suggest that $\mathrm{EZH} 2$, at least in certain B-cell lymphoma cell lines, may participate in the pathogenesis of this disease as these cells were notably affected by the EZH2 inhibitor DZNep. This supports the reported inhibition by potent EZH2 inhibitors in Pfeiffer cells (34); however, ribavirin was found to not affect EZH2 expression or H3K27 trimethylation. This indicates the potential weak inhibitory activity of ribavirin against EZH2. On the contrary, our study demonstrated that ribavirin notably inhibited the growth of lymphoma cell lines. These effects were more potent in the T-cell lymphoma cell line, which may depend, at least in part, on the activation of canonical immune pathways regulated by the key factors STAT1 and IFN- $\gamma$. The results of the present study provide insight into the effects of ribavirin, which warrants its analysis in preclinical and clinical studies to determine the potential of this drug as a candidate anticancer agent for the treatment of lymphoma.

\section{Acknowledgements}

Not applicable.

\section{Funding}

The present study was funded by Consejo Nacional de Ciencia y Tecnologia, grant 161915.

\section{Availability of data and materials}

The datasets used during the present study are available from the corresponding author upon reasonable request.

\section{Authors' contributions}

GDG, DCP, ASC, ACB, AGF, JDC and LTC performed the experiments and collected the data in regards to the cell culture, western blotting and RT-PCR. FBA, ACT and AHM performed the microarray experiments and analysis. ADG conceived and wrote the manuscript. All authors contributed to the discussion of the results and critically read and approved the manuscript and agree to be accountable for all aspects of the research in ensuring that the accuracy or integrity of any part of the work are appropriately investigated and resolved.

\section{Ethics approval and consent to participate}

Not applicable.

\section{Patient consent for publication}

Not applicable.

\section{Competing interests}

The authors state that they have no competing interests.

\section{References}

1. Sidwell RW, Robins RK and Hillyard IW: Ribavirin: An antiviral agent. Pharmacol Ther 6: 123-416, 1979.

2. Shepherd J, Jones J, Hartwell D, Davidson P, Price A and Waugh N: Interferon alpha (pegylated and non-pegylated) and ribavirin for the treatment of mild chronic hepatitis C: A systematic review and economic evaluation. Health Technol Assess 11: $1-205$, iii 2007.

3. De la Cruz-Hernandez E, Medina-Franco JL, Trujillo J, Chavez-Blanco A, Dominguez-Gomez G, Perez-Cardenas E, Gonzalez-Fierro A, Taja-Chayeb L and Dueñas-Gonzalez A: Ribavirin as a tri-targeted antitumor repositioned drug. Oncol Rep 33: 2384-2392, 2015.

4. Assouline S, Culjkovic B, Cocolakis E, Rousseau C, Beslu N Amri A, Caplan S, Leber B, Roy DC, Miller WH Jr and Borden KL: Molecular targeting of the oncogene eIF4E in acute myeloid leukemia (AML): A proof-of-principle clinical trial with ribavirin. Blood 114: 257-260, 2009.

5. Kentsis A, Topisirovic I, Culjkovic B, Shao L and Borden KL: Ribavirin suppresses eIF4E-mediated oncogenic transformation by physical mimicry of the 7-methyl guanosine mRNA cap. Proc Natl Acad Sci USA 101: 18105-18110, 2004.

6. Borroto-Esoda K, Myrick F, Feng J, Jeffrey J and Furman P: In vitro combination of amdoxovir and the inosine monophosphate dehydrogenase inhibitors mycophenolic acid and ribavirin demonstrates potent activity against wild-type and drug-resistant variants of human immunodeficiency virus type 1 . Antimicrob Agents Chemother 48: 4387-4394, 2004.

7. Casaos J, Huq S, Lott T, Felder R, Choi J, Gorelick N, Peters M, Xia Y, Maxwell R, Zhao T, et al: Ribavirin as a potential therapeutic for atypical teratoid/rhabdoid tumors. Oncotarget 9: 8054-8067, 2018.

8. Volpin F, Casaos J, Sesen J, Mangraviti A, Choi J, Gorelick N, Frikeche J, Lott T, Felder R, Scotland SJ, et al: Use of an anti-viral drug, Ribavirin, as an anti-glioblastoma therapeutic. Oncogene 36: 3037-3047, 2007.

9. Béguelin W, Popovic R, Teater M, Jiang Y, Bunting KL, Rosen M, Shen H, Yang SN, Wang L, Wang L, et al: EZH2 is required for germinal center formation and somatic EZH2 mutations promote lymphoid transformation. Cancer Cell 23: 677-692, 2013.

10. Sasaki D, Imaizumi Y, Hasegawa H, Osaka A, Tsukasaki K, Choi YL, Mano H, Marquez VE, Hayashi T, Yanagihara K, et al: Overexpression of Enhancer of zeste homolog 2 with trimethylation of lysine 27 on histone $\mathrm{H} 3$ in adult T-cell leukemia/lymphoma as a target for epigenetic therapy. Haematologica 96: 712-719, 2011.

11. Soumyanarayanan U and Dymock BW: Recently discovered EZH2 and EHMT2 (G9a) inhibitors. Future Med Chem 8: 1635-1654, 2016.

12. Peveling-Oberhag J, Arcaini L, Bankov K, Zeuzem S and Herrmann E: The anti-lymphoma activity of antiviral therapy in HCV-associated B-cell non-Hodgkin lymphomas: A meta-analysis. J Viral Hepat 23: 536-544, 2016.

13. Pettersson F, Yau C, Dobocan MC, Culjkovic-Kraljacic B, Retrouvey H, Puckett R, Flores LM, Krop IE, Rousseau C, Cocolakis E, et al: Ribavirin treatment effects on breast cancers overexpressing eIF4E, a biomarker with prognostic specificity for luminal B-type breast cancer. Clin Cancer Res 17: 2874-2884, 2011.

14. Pettersson F, Del Rincon SV, Emond A, Huor B, Ngan E, $\mathrm{Ng}$ J, Dobocan MC, Siegel PM and Miller WH Jr: Genetic and pharmacologic inhibition of eIF4E reduces breast cancer cell migration, invasion, and metastasis. Cancer Res 75: 1102-1112, 2015.

15. Sharma S, Baksi R and Agarwal M: Repositioning of anti-viral drugs as therapy for cervical cancer. Pharmacol Rep 68: 983-989, 2016. 
16. Xi C, Wang L, Yu J, Ye H, Cao L and Gong Z: Inhibition of eukaryotic translation initiation factor $4 \mathrm{E}$ is effective against chemo-resistance in colon and cervical cancer. Biochem Biophys Res Commun 503: 2286-2292, 2018.

17. Richard SM and Martinez Marignac VL: Sensitization to oxaliplatin in HCT116 and HT29 cell lines by metformin and ribavirin and differences in response to mitochondrial glutaminase inhibition. J Cancer Res Ther 11: 336-340, 2015.

18. Kosaka T, Nagamatsu G, Saito S, Oya M, Suda T and Horimoto K: Identification of drug candidate against prostate cancer from the aspect of somatic cell reprogramming. Cancer Sci 104: 1017-1026, 2013

19. Culjkovic B and Borden KL: Understanding and targeting the eukaryotic translation initiation factor eIF4E in head and neck cancer. J Oncol 2009: 981679, 2009.

20. Attar-Schneider O, Drucker L and Gottfried M: Migration and epithelial-to-mesenchymal transition of lung cancer can be targeted via translation initiation factors eIF4E and eIF4GI. Lab Invest 96: 1004-115, 2016.

21. Tan K, Culjkovic B, Amri A and Borden KL: Ribavirin targets eIF4E dependent Akt survival signaling. Biochem Biophys Res Commun 375: 341-345, 2008.

22. Volpon L, Osborne MJ, Zahreddine H, Romeo AA and Borden KL: Conformational changes induced in the eukaryotic translation initiation factor eIF4E by a clinically relevant inhibitor, ribavirin triphosphate. Biochem Biophys Res Commun 434: 614-619, 2013.

23. Borden KL and Culjkovic-Kraljacic B: Ribavirin as an anti-cancer therapy: Acute myeloid leukemia and beyond? Leuk Lymphoma 51: 1805-1815, 2010.

24. Culjkovic-Kraljacic B, Fernando TM, Marullo R, Calvo-Vidal N, Verma A, Yang S, Tabbò F, Gaudiano M, Zahreddine H, Goldstein RL, et al: Combinatorial targeting of nuclear export and translation of RNA inhibits aggressive B-cell lymphomas. Blood 127: 858-868, 2016.
25. Rutherford SC, Stewart EN, Chen Z, Chadburn A, Wehrli NE, van Besien K, Martin P, Furman RR, Leonard JP and Cerchietti L: The eIF4E inhibitor ribavirin as a potential antilymphoma therapeutic: Early clinical data. Leuk Lymphoma 59: 256-258, 2018.

26. Dunn GP, Koebel CM and Schreiber RD: Interferons, immunity and cancer immunoediting. Nat Rev Immunol 6: 836-848, 2006.

27. Ferrantini M, Capone I and Belardelli F: Interferon-alpha and cancer: Mechanisms of action and new perspectives of clinical use. Biochimie 89: 884-893, 2007.

28. Belardelli F, Ferrantini M, Proietti E and Kirkwood JM: Interferon-alpha in tumor immunity and immunotherapy. Cytokine Growth Factor Rev 13: 119-134, 2002.

29. Rotman Y, Noureddin M, Feld JJ, Guedj J, Witthaus M, Han H, Park YJ, Park SH, Heller T, Ghany MG, et al: Effect of ribavirin on viral kinetics and liver gene expression in chronic hepatitis $\mathrm{C}$. Gut 63: 161-169, 2014.

30. Sun WH, Pabon C, Alsayed Y, Huang PP, Jandeska S, Uddin S, Platanias LC and Rosen ST: Interferon-alpha resistance in a cutaneous T-cell lymphoma cell line is associated with lack of STAT1 expression. Blood 91: 570-576, 1998.

31. Sugaya M, Tokura Y, Hamada T, Tsuboi R, Moroi Y, Nakahara T, Amano M, Ishida S, Watanabe D, Tani M, et al: Phase II study of i.v. interferon-gamma in Japanese patients with mycosis fungoides. J Dermatol 41: 50-56, 2014

32. Kyvernitakis A,Duvic M,MahalePand Torres HA:Interferon-based treatment for patients with mycosis fungoides and hepatitis $\mathrm{C}$ virus infection: A case series. Am J Clin Dermatol 15: 451-456, 2014.

33. Care MA, Westhead DR and Tooze RM: Gene expression meta-analysis reveals immune response convergence on the IFN $\gamma$-STAT1-IRF1 axis and adaptive immune resistance mechanisms in lymphoma. Genome Med 7: 96, 2015.

34. Woo J, Kim HY, Byun BJ, Chae CH, Lee JY, Ryu SY, Park WK, Cho $\mathrm{H}$ and Choi G: Biological evaluation of tanshindiols as EZH2 histone methyltransferase inhibitors. Bioorg Med Chem Lett 24: 2486-2492, 2014 